\title{
The ultimate dental book since 1920
}

\author{
By Helen Nield
}

A s a way of marking the BDA library's centenary we carried out a survey throughout 2020 to try and find the ultimate dental book since the library opened in 1920 .

Our first survey looked to find the ultimate book in various categories and the results of that were:

- Dental public health - The Scientific Basis of Dental Health [now oral health] Education

- Endodontics - Cohen's Pathways of the Pulp

- Dental implants - Contemporary Implant Dentistry by Misch

- Orthodontics - Contemporary Orthodontics by Proffit and Fields

- Periodontology - Glickman's Clinical Periodontology now known as Newman and Carranza's Clinical Periodontology

- Prosthodontics - Fundamentals of Fixed Prosthodontics by Shillingburg, Hobo and Whitsett

- Restorative dentistry - Sturdevant's Art and Science of Operative Dentistry.

In addition to asking people to vote by category a further six titles were presented as possible candidates and more than one of these could be chosen by participants. Scully's Medical Problems in Dentistry gained the most votes out of these, followed by Andreasen's [Textbook and Color Atlas of] Traumatic Injuries to the Teeth. Finally, we asked for other suggestions and Cawson's Essentials of Oral Pathology and Oral Medicine was mentioned several times.

These ten titles were then put forward into a final survey to find the 'book of books' and we also asked for reasons why certain titles had been chosen. See Figure 1.

\section{Least popular}

In last place was Contemporary implant dentistry by Misch which perhaps reflects the focused nature of implant dentistry. In joint eighth place were Contemporary Orthodontics and [Textbook and Color Atlas of] Traumatic Injuries of the Teeth. The latter obviously meant a great deal to one respondent who said: 'This is the ultimate research-led guide on the management of a clinical aspect that can have such a significant impact on patient welfare. Doing it right first time every time could have been the mantra of this book'. As far as Proffit's orthodontic book goes it was voted for presumably by an orthodontist who declared: 'It was my bible, written by a real jobbing genius orthodontist'.

\section{Mid-table finish}

In joint sixth place were The Scientific Basis of Dental Health [now oral health] Education and Sturdevant's Art and Science of Operative Dentistry. Moving up to fifth place we got Shillingburg's Fundamentals of Fixed Prosthodontics which was voted for by one person because it is the 'gold standard which everyone refers to for basics of design' and another simply said 'Just a beautiful book and still relevant'. Just missing out on the top three was Clinical Periodontology by I. Glickman and F. A. Carranza. This received a number of great comments amongst which were 'Foundation and basis for oral health', 'Comprehensive coverage of diagnosis, pathology and treatment, very well written and illustrated' and finally: 'It is ever more clear that the periodontium is the key to health, and the basis of all of dentistry. And this book has incredible depth and represents very well not only for the periodontal but for all of the dental community'.

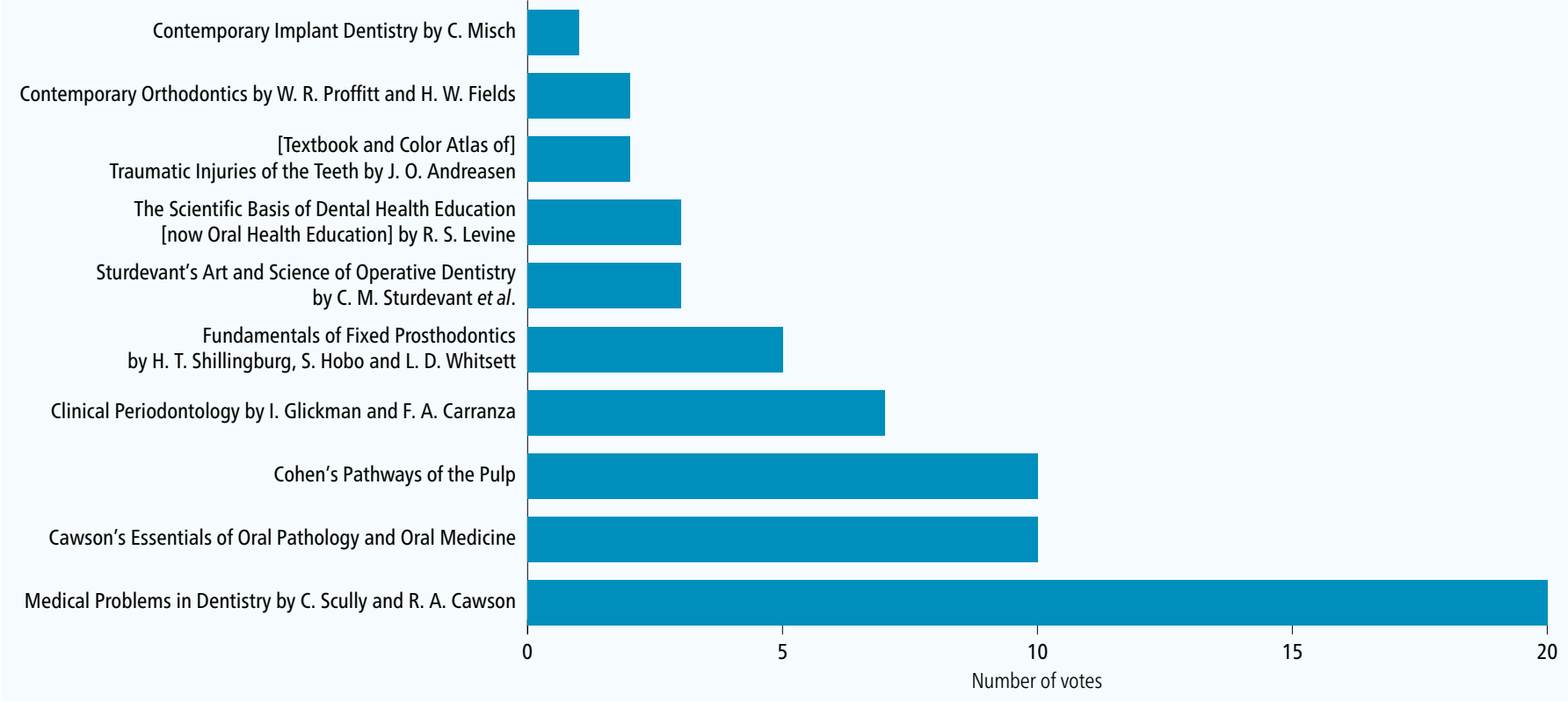




\section{Joint second}

Second place was tied between Cohen's Pathways of the Pulp and Cawson's Essentials of Oral Pathology and Oral Medicine with $15.9 \%$ of the vote each. There was only one comment made about Cohen's book but it was a good one: 'Scientific evidence with practicality. I have been reading this book frequently again and again'. Cawson's book seems to have brought out the nostalgic element in those that voted for it with comments like 'Dental school memories!' and 'This was my text book at dental school, it got me through finals and helped me understand things like oral ulceration which I still recall 30 years later', and one of my favourites: 'Known as Noswac, had to know it backwards to pass finals'! Others commented on its clarity: 'It is beautifully presented and informative when dealing with a difficult subject', 'Nice, concise, easy to understand' and 'Clear, defined text - covers all pathologies and presentations - written by one of the profession's greatest members'. One final elegant comment was: 'It serves to reinforce the emerging importance of the oral biome in systemic health and is beautifully illustrated'.

\section{The winner!}

The winner, voted ultimate dental book of the last hundred years with $31.7 \%$ of the vote, was of course Scully's Medical Problems in Dentistry. Still massively popular today in its latest seventh edition, it was accessed 237 times in our ebook collection through 2020 and 20 times already in January this year.

A lot of the comments about it referred to the need to have it ready to consult at any time. For example: 'It's the only textbook that I feel I need to keep in my surgery rather than at home because it is so useful'; 'It's one of the only books that I find very useful on a weekly basis'; and: 'It is of immense practical use and one I still use today as a reference in the surgery and have updated with each new edition'. One dentist described the trust they put in it by saying that it gave them 'the ability to view each patient with confidence that I am armed with the latest information. One observation made was: 'I feel in my five years of practice, this book by the late Professors Scully and Cawson has been the most helpful in my government and private careers as I see a lot of patients with a variety of illnesses and comorbid conditions. This book takes out the guesswork by explaining in simple terms how to handle medical conditions in a dental setting. It's so good I don't need Google. I will NEVER throw it away'.

Finally, summing everything up was this response: 'When I was a dental student in the 1990s this book was the definitive reference work for the medical matters we faced as students and would face in practice. When I completed my postgraduate training I was inspired by Professor Scully to write my first book in 2013, now in the BDA library. When Professor Scully commented favourably and students were inspired by my writing I finally realised after nearly 30 years the true value of Scully and Cawson's Medical Problems in Dentistry: It is the ultimate book in dentistry not only of the last 100 years, but perhaps for the working lives of those who will continue to use the next editions into the next 100 years too'.

Thank you to everybody that voted and commented - maybe we'll do this again in another 100 years!

\section{Online jaw surgery resource celebrates five years}

Your Jaw Surgery, an information resource for patients (and clinicians) from the British Orthodontic Society (BOS), has celebrated its fifth birthday. Created to help patients better understand jaw surgery, it includes videos detailing what patients can expect at every stage of the jaw surgery journey, animated films, downloadable advice sheets as well as patients sharing their experiences and stories.

The most recent statistics show that since upload of the videos in 2016, there have been more than 1 million impressions and over 200,000 video views. These views have been across the whole of the UK and indeed further afield. The lack of reliable, high quality information not just in the UK but worldwide is further illustrated by more than $10 \%$ of total views being from overseas.

Caroline McCarthy, Consultant Orthodontist and Chair of the organising committee of Your Jaw Surgery, said: 'Your Jaw Surgery was inspired by the success of the BOS Jaw Surgery DVD but with a desire to update the information and to enable online access for patients considering surgical options. It has now been going for five years and the statistics speak for themselves.

'We are all really proud of this piece of work and are glad that it is staying current and relevant to more than 3,000 people who undergo orthognathic treatment in the UK every year. It also helps those people with a dentofacial condition to accept this and decide that treatment is not for them. We know, as hospital consultants, that hospital departments are recommending the website to the patients who are seeking orthognathic treatment.

'We would also like to encourage our general and specialist colleagues to access the information too so that their patients can be directed to it and benefit from all the information available. It will help GDPs gain greater insight into this complex multi-disciplinary treatment and would also help specialist orthodontists with the many adult patients seeking orthodontic treatment. Many of these wish to accept the skeletal aspect of their problem and the information on this website can really help patient understanding for the informed consent process.'

https://www.bos.org.uk/Your-Jaw-Surgery

\section{BDA AGM}

The West Lancashire, West Cheshire and North Wales BDA Branch AGM will be held online on Wednesday 24 March 2021 at 19:45.

Please ensure you register your interest in attending at www.bda.org/bse in order to receive the link to access the AGM or email branchsectionevents@bda.org. 